\title{
Comparison of efficacy and tolerance of short- duration open-ended ureteral catheter drainage and tamsulosin administration to indwelling double J stents following ureteroscopic removal of stones
}

\author{
Vikram S Chauhan *, Rajeev Bansal, Mayuri Ahuja
}

\section{A B S T R A C T}

Objectives: To evaluate the efficacy of shortduration, open-ended ureteral catheter drainage as a replacement to indwelling stent, and to study the effect of tamsulosin on stent-induced pain and storage symptoms following uncomplicated ureteroscopic removal of stones.

Design: Prospective randomised study.

Setting: School of Medical Sciences and Research, Sharda University, Greater Noida, India.

Patients: Patients who underwent ureteroscopic removal of stones for lower ureteral stones between November 2011 and January 2014 were randomly assigned into three groups. Patients in group $1 \quad(n=33)$ were stented with 5-French double J stent for 2 weeks. Patients in group $2(n=35)$ were administered tablet tamsulosin $0.4 \mathrm{mg}$ once daily for 2 weeks in addition to stenting, and those in group $3(n=31)$ underwent 5-French open-ended ureteral catheter drainage for 48 hours.

Main outcome measures: All patients were evaluated for flank pain using visual analogue scale scores at days $1,2,7$, and 14, and for storage (irritative) bladder symptoms using International Prostate Symptom Score on days 7 and 14, and for quality-of-life score (using International Prostate Symptom Score) on day 14.
Results: Of the 99 patients, visual analogue scale scores were significantly lower for groups 2 and 3 $(\mathrm{P}<0.0001)$. The International Prostate Symptom Scores for all parameters were lower in patients from groups 2 and 3 compared with group 1 both on days 7 and $14(\mathrm{P}<0.0001)$. Analgesic requirements were similar in all three groups.

Conclusion: Open-ended ureteral catheter drainage is equally effective and better tolerated than routine stenting following uncomplicated ureteroscopic removal of stones. Tamsulosin reduces storage symptoms and improves quality of life after ureteral stenting.

\section{Hong Kong Med J 2015;21:124-30}

\section{DOI: 10.12809/hkmj144292}

${ }^{1}$ VS Chauhan *, MB, BS, MS (Surgery)

${ }^{1}$ R Bansal, MB, BS, MS (Surgery)

2 M Ahuja, MB, BS, DGO

School of Medical Sciences \& Research, Sharda University, Greater Noida (U.P.) 201306, India

2 Kokila Dhirubhai Ambani Hospital \& Medical Research Institute, Andheri West, Mumbai 400053, India

* Corresponding author: vsing73@rediffmail.com

New knowledge added by this study

- This study shows that short-duration (up to 48 hours) ureteral drainage following ureteroscopic removal of stones (URS) has better efficacy and tolerance than indwelling stent placement with respect to the need for postoperative drainage. Hence, this can be a replacement for double J stenting.

- Routine tamsulosin administration in patients with indwelling stents following URS has beneficial effects not only on irritative bladder symptoms but also on flank pain (both persistent and voiding).

Implications for clinical practice or policy

- Replacement of stents with short-duration open-ended ureteral catheter drainage provides early and more rehabilitation to the patients following URS. This is a viable option because there is no need for follow-up for stent-related symptoms, or maintaining records for planning its removal (no lost or retained stents).

- It avoids a second invasive endoscopic procedure of stent removal, thereby reducing the medical and financial burden on the patient (especially important in developing countries). Patients are more likely to undergo URS again if required in the future (with stone recurrence) than opt for less effective or expensive choices like medical management, shock wave lithotripsy, or alternative forms of medicine.

- In stented patients, tamsulosin administration improves the overall quality of life, and makes the period with stent in situ more bearable and asymptomatic. 


\section{Introduction}

Ureteroscopic removal of stones (URS) is the standard endoscopic method for treatment of lower ureteric calculi. In recent times, this procedure does not require routine dilatation of ureteric orifice due to the availability of small-calibre rigid ureteroscopes that can be easily manipulated into the ureter in most of the cases.

Once the stones are removed, an indwelling ureteral double $J$ stent is placed which remains in situ postoperatively for a period of 2 to 4 weeks. This is dependent on a variety of factors such as the difficulty in removal of stones, any mucosal injury, and associated stricture of the ureter or its meatus. Finney ${ }^{1}$ was the first to describe the use of double J stents in the year $1978 .^{2}$ The use of stents has proved to be beneficial as seen in various studies, because they prevent or reduce the occurrence of ureteric oedema, clot colic, and subsequent development of secondary ureteric stricture in cases with mucosal injury or difficult stones. ${ }^{3-5}$ However, the use of ureteral stents is not without its attendant complications. Patients may develop flank pain, haematuria, clot retention, dysuria, frequency, and other irritative bladder symptoms following stent placement in the postoperative period. Hence, many authors have questioned the need for routine placement of stents or their early removal. ${ }^{6}$ Recently, researchers have proposed that the irritative and other symptoms due to stents can be reduced or overcome by the use of alpha blockers. ${ }^{7}$ With this background knowledge, we conducted a prospective randomised study with the aim to assess the efficacy of oral tamsulosin for 14 days following stenting, and efficacy of an open-ended ureteral catheter for 48 hours instead of a stent as viable options in patients who underwent uncomplicated URS for lower ureteric stones.

\section{Methods}

This study was conducted at School of Medical Sciences and Research, Sharda University, Greater Noida, India, after obtaining due clearance from the ethics committee. Recruitment of patients was done over a period from November 2011 to January 2014 and included a total of 99 patients who underwent URS for lower ureteric stones.

Inclusion criteria were lower ureteric stones defined as those imaged below the lower border of sacroiliac joint of up to $10 \mathrm{~mm}$ in diameter on computed tomography. Stones larger than $10 \mathrm{~mm}$ in diameter, presence of ipsilateral kidney stones, cases with lower ureteric or meatal stricture requiring dilatation, and cases which had significant mucosal injury (flap formation) per-operatively were excluded.

All patients underwent URS under spinal

\section{接受輸尿管鏡下去除結石手術的病人，比較其短 期使用開放式輸尿管導管引流和置雙J支架後處 方坦索羅辛的療效和病人耐受性}

\author{
Vikram S Chauhan, Rajeev Bansal, Mayuri Ahuja
}

目的：對於輸尿管鏡去除結石手術後的病人，評估他們短期使用開放 式輸尿管置管引流代替留置支架的療效, 並研究術後處方坦索羅辛對 於病人因支架引起的疼痛和儲尿期症狀的療效。

設計：前瞻性隨機對照研究。

安排：印度大諾伊達地區Sharda大學內的醫學科學研究院。

患者：把2011年11月至2014年1月期間因輸尿管下段結石而須進行 輸尿管鏡去除結石手術的病人隨機分為三組。第一組患者（共33例） 被植入5-French雙J管, 為期兩週。第二組患者（共35例）除了植入 相同支架，還被處方每日服食坦索羅辛（tamsulosin）0.4毫克，為期 兩週。第三組患者（共31例）則被植入5-French開放式輸尿管導管引 流, 維持48小時。

主要結果測量 : 研究期間為所有患者評估以下指數：在第 1 、2、7及 14天使用視覺模擬量表評分（VAS）評估患者的腰痛程度；在第7及 14 天使用國際前列腺症狀評分（IPSS）評估患者的儲尿期（易激性） 症狀；以及在第 14 天使用IPSS評估患者的生活質素。

結果 : 共99名患者參與本研究。第二組患者和第三組患者的VAS顯著 較低 $(\mathrm{P}<0.0001)$ 。第二組和第三組的第7及 14 天IPSS的所有參數均 低於第一組患者 $(\mathrm{P}<0.0001)$ 。三組患者對鎮痛藥的需求相若。

結論：進行簡單的輸尿管鏡去除結石手術後, 開放式輸尿管導管引流 與常規支架術同樣有效, 而且耐受性更高。植入輸尿管支架後服食坦 索羅辛能減少儲尿期（易激性）症狀, 從而提高患者的生活質素。

anaesthesia using an 8-French rigid ureteroscope, and stones requiring fragmentation were broken with a pneumatic lithoclast and these fragments were retrieved with forceps. One surgeon performed all the interventional procedures during the study period.

The patients were randomly assigned to three groups using randomisation table. On the random number table, we chose an arbitrary place to start and then read towards the right of the table from that number. We used a number read on the table from 1 to 3 to assign cases to group 1, a number from 4 to 6 to assign to group 2, and a number from 7 to 9 to assign cases to group 3 (a value of 0 was ignored). A duty doctor prepared 120 serially numbered slips of papers (indicating the number of enrolment) by following the above randomisation protocol and had written in them the group to which a new case was to be assigned. The chits were folded, stapled, and stacked in a box and stored in the operating theatre. After completion of the URS, the floor nurse opened the chit to reveal the appropriate enrolment number and the group (group 1, 2 or 3 ) to which the patient would go, thereby deciding further intervention. 
Patients in group 1 underwent double J stent placement following URS for a period of 2 weeks. Patients in group 2 were administered tablet tamsulosin $0.4 \mathrm{mg}$ once daily for 2 weeks in addition to double J stent. Patients in group 3 underwent placement of an open-ended 5-French ureteral catheter following the URS procedure, the distal end of which was introduced into the lumen of Foley catheter. Both the ureteric and Foley catheter were removed on the second postoperative day in group 3 patients.

A 5-French 25-cm double J stent was used for stenting and the duration of surgery was recorded as time from the introduction of ureteroscope to the placement of Foley catheter. Postoperatively, patients were assessed for flank pain (persistent or voiding) by asking them to report the pain on a visual analogue scale (VAS) of 0 to 10 (0 being no pain and 10 pain as severe as it could be) on postoperative days $1,2,7$, and 14 . Patients were also asked to report storage symptoms using the International Prostate Symptom Score (IPSS) at 1 and 2 weeks postoperatively to assess irritative bladder symptoms, while the IPSS quality-of-life index was assessed at 2 weeks postoperatively. All stented patients were discharged with tablet levofloxacin $250 \mathrm{mg}$ orally once daily for 2 weeks as suppressive prophylaxis for infection.

Patients who had an indwelling double J stent underwent stent removal after 2 weeks by cystoscopy under local anaesthesia using $2 \%$ lidocaine jelly supplemented with intravenous injection of pentazocine $30 \mathrm{mg}$ on a patient-need basis, and were asked to report the pain experienced during the stent removal on a VAS. Administration and reporting of VAS scores was done by the floor manager (administrative personnel) with assistance from nurse on duty for the in-patients (wards), while an intern and nurse on duty for out-patients on follow-up was done in local language (Hindi). All of these staff assessing VAS were blinded and had no direct influence or active role in the treatment or assessment protocol.

All patients on completion of 2 weeks of surgery were asked, "Whether you would opt for the same procedure again as treatment if you develop ureteral stones in the future?" Patients complaining of pain postoperatively were given injection tramadol $50 \mathrm{mg}$ intravenously if needed. If pain persisted, patients were given intravenous injection of pentazocine 30 mg. All patients underwent intravenous urography after 1 month of procedure to document stone clearance and development of ureteral stricture. Patients were asked to report to the out-patient department if any other complications occurred following discharge.

The sample size was estimated with the following logic. We assumed the margin of error that could be accepted as 5\%, with a confidence level of $90 \%$ and population size of 45 (cases that were admitted with flank pain and require URS for stones), in our institution the number of cases who undergo URS typically in a year would be roughly around 45 to 50 . Assuming the response distribution to be $50 \%$, with the above assumptions, the sample size calculated was 39 , using the following formula:

Sample size $\mathrm{n}$ and margin of error $\mathrm{E}$ are given by $x=Z(\mathrm{c} / 100)^{2} r(100-r)$

$n=N x /\left((N-1) E^{2}+x\right)$

$E=\operatorname{Sqrt}[(N-n) x / n(N-1)]$

where $N$ is the population size, $r$ is the fraction of responses that we are interested in, and $Z(c / 100)$ is the critical value for the confidence level $c$.

This calculation is based on the normal distribution, and assumes that there are more than 30 samples and a power of 80 . Hence, we chose to recruit approximately 35 patients in each arm of study.

\section{Statistical analyses}

After collation of data, Student's $t$ test and Pearson Chi squared test were used to analyse the three groups for age, sex, stone size, and operating time. We also comparatively evaluated the severity of flank pain on postoperative days 1,2 and weeks 1 and 2 , and the IPSS for each group regarding storage symptoms, total IPSSs at postoperative weeks 1 and 2 , and the quality-of-life index at 2 weeks. Results from groups 2 and 3 were compared with group 1 to draw conclusions. Fisher's exact test and Pearson Chi squared tests were used to compare the number of patients who needed intravenous analgesics due to severe postoperative pain and to examine the response to our question, "Whether you would opt for the same procedure again as treatment if you develop ureteral stones in the future?"

\section{Results}

There was no significant variation in the three groups with regard to variables like age, sex, stone size, and operating time (Table 1). The VAS score for flank pain, however, showed significant differences among the three groups. On postoperative day 1, the mean ( \pm standard deviation) VAS scores in groups 1,2 , and 3 were $2.73 \pm 1.14,2.34 \pm 1.12$, and $2.35 \pm 0.86$ respectively, but were not statistically significant (groups 1 and 2, $\mathrm{P}=0.17$; groups 1 and $3, \mathrm{P}=0.15$ ). On day 7 , the mean VAS scores for groups 2 and 3 were $0.97 \pm 0.77$ and $1.00 \pm 0.72$ respectively, which were significantly lower than group 1 score of $2.85 \pm$ $1.52(\mathrm{P}<0.0001)$. On day 14 , the mean VAS scores for groups 1,2 , and 3 were $2.48 \pm 1.40,0.66 \pm 0.67$, and $0.55 \pm 0.56$ respectively $(\mathrm{P}<0.0001)$. This amounted to significantly greater pain in group 1 patients as compared with those in groups 2 and 3 (for groups 
TABLE I. General characteristics of study patients

\begin{tabular}{|c|c|c|c|c|c|}
\hline \multirow[t]{2}{*}{ Characteristic } & \multicolumn{3}{|c|}{ Mean \pm standard deviation } & \multirow{2}{*}{$\begin{array}{c}\text { P value } \\
\text { (groups 1-2) }\end{array}$} & \multirow{2}{*}{$\begin{array}{c}\text { P value } \\
\text { (groups 1-3) }\end{array}$} \\
\hline & Group $1^{*}(n=33)$ & Group $2 †(n=35)$ & Group $3 \neq(n=31)$ & & \\
\hline Age (years) & $37.45 \pm 7.78$ & $36.83 \pm 8.32$ & $35.61 \pm 6.50$ & $0.75 \S$ & $0.31 \S$ \\
\hline Sex (male:female) & $17: 16$ & $19: 16$ & $17: 14$ & $0.82 \|$ & $0.79 \|$ \\
\hline Size of stone (mm) & $8.36 \pm 1.18$ & $8.66 \pm 1.09$ & $8.39 \pm 1.21$ & $0.29 \S$ & $0.94 \S$ \\
\hline Operating time (mins) & $36.85 \pm 5.28$ & $37.00 \pm 5.62$ & $36.23 \pm 5.19$ & $0.91 \S$ & $0.64 \S$ \\
\hline
\end{tabular}

* Patients stented for 2 weeks

$\dagger$ Patients stented for 2 weeks + tablet tamsulosin 0.4 mg once daily for 2 weeks

$\neq$ Patients drained with 5-French open-ended catheter for 2 days

$\S$ Student's independent $t$ test

\| Chi squared test

1-2 and 1-3, $\mathrm{P}<0.0001$; Fig 1). Among those stented, the mean VAS score for stent removal using $2 \%$ lidocaine jelly was $3.76 \pm 1.55$ but the mean VAS score for stent removal with regard to sex (male:female $=$ $36: 32$ ) was $4.97 \pm 0.80$ and $2.41 \pm 0.96$, respectively and this was statistically significant $(\mathrm{P}<0.0001)$.

Analyses of IPSS on both postoperative days 7 and 14 for bladder sensation, frequency, urgency, nocturia, and the sum total of IPSS showed there was significant decrease in group 2 as compared with group 1 for all four parameters $(\mathrm{P}<0.0001)$. Group 3 patients had minimal mean IPSS scores to begin with (Table 2). The mean quality-of-life scores for groups 1,2 , 3 were $4.00 \pm 0.92,1.37 \pm 0.86$, and $0.52 \pm 0.50$ respectively, and this was significantly better for groups 2 and 3 compared with group 1 $(\mathrm{P}<0.00001$; Fig 2 and Table 3$)$.

Nine patients in group 1, 11 in group 2, and seven in group 3 complained of pain requiring injection of tramadol $50 \mathrm{mg}$ (Table 3). Only one patient (stentonly group) further required intravenous injection of pentazocine $30 \mathrm{mg}$ due to persistent pain. No patient in any group required intravenous analgesic after day 2 making analgesic need similar in all groups. One patient who was stented and had not received tamsulosin reported gross haematuria on the sixth day, which required readmission and catheterization with bladder wash, and the haematuria responded to conservative treatment. Beyond the 2-week period, no patient reported any other complication during the 2-month follow-up.

In this study, 20, 29, and all patients in groups 1,2 , and 3 respectively showed willingness for undergoing same procedure in future if needed. This showed that a higher percentage of patients in groups 2 and 3 were willing for repeated surgery (if needed) than in group 1 , which was statistically significant (for groups $1-2, \mathrm{P}=0.04$, and for groups 1-3, $\mathrm{P}=0.0003$; Table 3). Two patients from the open drainage group were lost to follow-up after 7 days. There was no crossover from one group to the other once assigned.

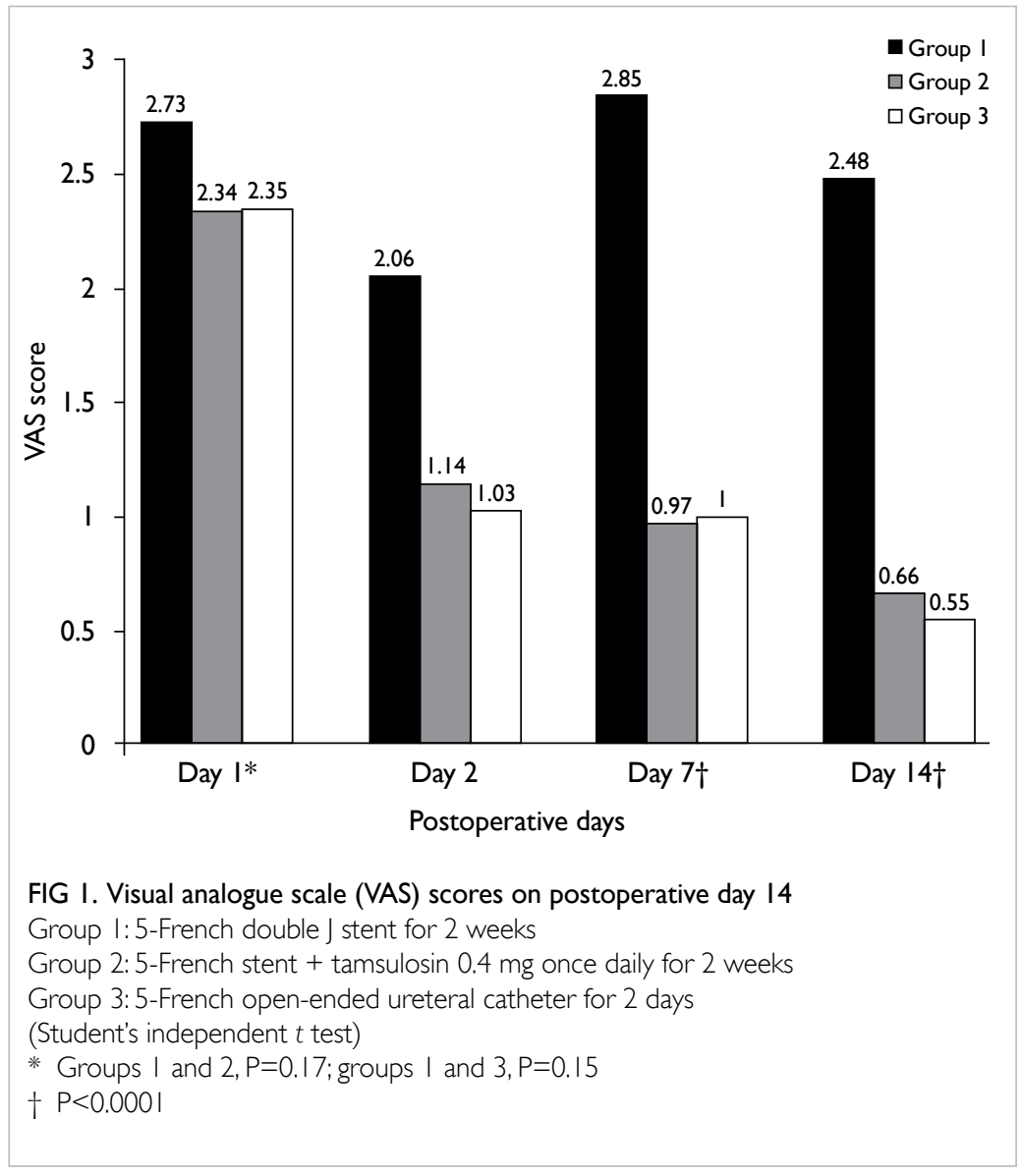

\section{Discussion}

Indwelling double J stents are routinely placed following URS to prevent flank pain and secondary ureteral strictures. ${ }^{4,8,9}$ However, duration-dependent symptoms due to ureteral stents have been well documented. Pollard and Macfarlane ${ }^{10}$ reported stent-related symptoms in $18(90 \%)$ out of 20 patients who had indwelling ureteral stents following URS. Bregg and Riehle ${ }^{11}$ reported that symptoms such as gross haematuria (42\%), dysuria (26\%), and flank pain $(30 \%)$ appeared in stented patients prior to 
being taken up for shock wave lithotripsy. Stoller et $\mathrm{al}^{8}$ documented ureteral stent-related symptoms, like flank pain, frequency, urgency, and dysuria, in at least

TABLE 2. Mean ( \pm standard deviation) International Prostate Symptom Scores (IPSS) according to groups on postoperative day 7

\begin{tabular}{lccl}
\hline IPSS & Group 1* & Group 2† & Group 3¥ \\
\hline Bladder sensation & $4.09 \pm 0.75$ & $1.77 \pm 0.90$ & $0.03 \pm 0.18$ \\
Frequency & $3.85 \pm 0.89$ & $1.60 \pm 0.83$ & $1.06 \pm 0.72$ \\
Urgency & $2.36 \pm 1.10$ & $0.40 \pm 0.60$ & $0.13 \pm 0.34$ \\
Nocturia & $1.30 \pm 0.94$ & $0.23 \pm 0.54$ & 0.00 \\
Total of IPSS symptoms & $11.61 \pm 2.64$ & $4.00 \pm 2.03$ & $1.23 \pm 0.71$ \\
\hline
\end{tabular}

* Patients stented for 2 weeks

† Patients stented for 2 weeks + tablet tamsulosin 0.4 mg once daily for 2 weeks

$\neq$ Patients drained with 5-French open-ended catheter for 2 days

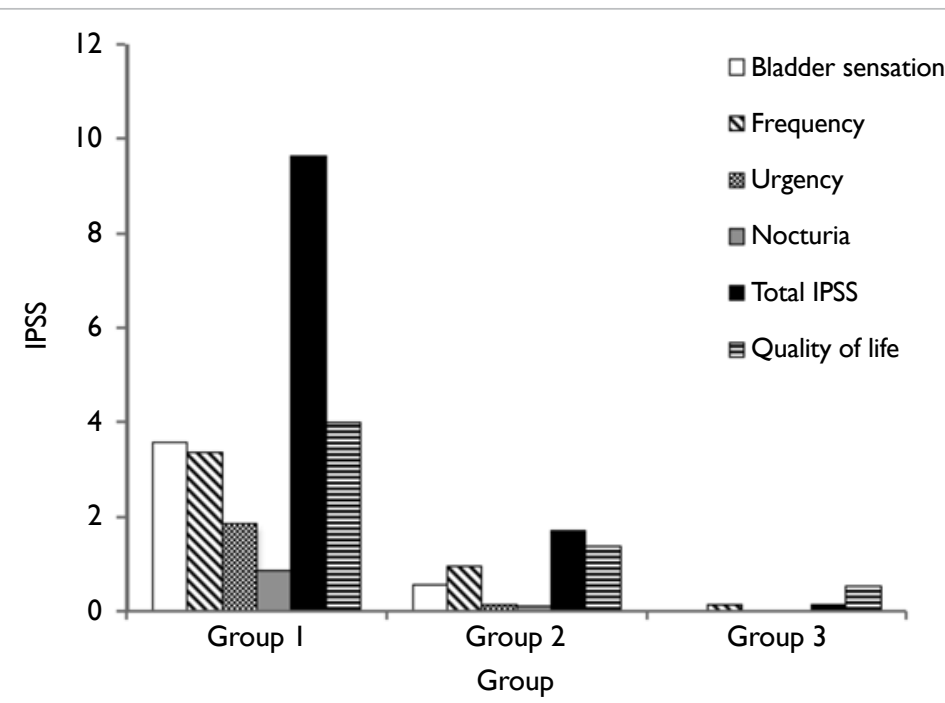

FIG 2. International Prostate Symptom Score (IPSS) and quality-of-life score on postoperative day 14

Group I: 5-French double I stent for 2 weeks

Group 2: 5 -French stent + tamsulosin $0.4 \mathrm{mg}$ once daily for 2 weeks

Group 3: 5-French open-ended ureteral catheter for 2 days
$50 \%$ of patients who had an indwelling ureteral stent. In a series by Han et $\mathrm{al},{ }^{12}$ haematuria was reported as the most common symptom (69\%) followed by dysuria (45.8\%), frequency (42.2\%), lower abdominal pain during voiding (32.2\%), and flank pain (25.4\%). Most studies report that apart from urgency and dysuria (which improve with time), there is no relief in other symptoms till the stent is removed.

Wang et $\mathrm{al}^{7}$ showed that administration of $\alpha$ blocker (tamsulosin) in stented patients improves flank pain and IPSS storage symptoms, along with an overall improvement in quality of life. They reported mean scores of frequency, urgency, nocturia as 3.7, 3.82, 2.01 in stented patients and 1.55, 1.43, 0.65 in those who received tamsulosin for 2 weeks, respectively. The mean score of quality of life in IPSS was 4.21 in stented group and 1.6 in stented + tamsulosin group. Moon et $\mathrm{al}^{13}$ reported that when compared with stenting, all the storage categories of the IPSS were significantly lower in the 1-day ureteral stent group $(P<0.01)$. Although the VAS scores were not significantly different on postoperative day 1 , it was significantly lower in the 1-day ureteral catheter group on postoperative days 7 and $14(\mathrm{P}<0.01) .{ }^{13}$

In our study, the mean total IPSS score at 2 weeks postoperatively was $9.64,1.71$, and 0.13 for groups 1, 2, and 3 respectively (Fig 2 ). We also found that the mean VAS scores for flank pain and the mean IPSS scores of bladder sensation, frequency, urgency, nocturia, were significantly higher in patients in group 1 when compared with groups 2 and 3 (Figs 1 and 2). These findings suggest that the indwelling double $\mathrm{J}$ stent causes time-dependent pain and storage symptoms due to persistent bladder irritation and administration of tamsulosin did significantly decrease symptoms. Our patients who received tamsulosin also fared much better on the quality-of-life index at both 1 and 2 weeks postoperatively than the group with stent placement only (mean score, 1.37 and 4.00 respectively), while those who underwent open-ended catheter drainage

TABLE 3. Pain requiring analgesia, quality of life, and willingness to opt for the same procedure again with stone recurrence among the groups

\begin{tabular}{|c|c|c|c|c|c|}
\hline & Group 1* & Group 2† & Group 3‡ & $P$ value (groups 1-2) & $P$ value (groups $1-3$ ) \\
\hline No. of patients & 33 & 35 & 31 & - & - \\
\hline Intravenous analgesic required & 9 & 11 & 7 & $0.79 \S$ & $0.78 \S$ \\
\hline Mean ( \pm standard deviation) quality-of-life score & $4.00 \pm 0.92$ & $1.37 \pm 0.86$ & $0.52 \pm 0.50$ & $<0.00001 \|$ & $<0.000001 \|$ \\
\hline Willingness for re-surgery & 20 & 29 & 31 & $0.04 \uparrow$ & $0.0003 \#$ \\
\hline
\end{tabular}

\footnotetext{
* Patients stented for 2 weeks

† Patients stented for 2 weeks + tablet tamsulosin 0.4 mg once daily for 2 weeks

$\mp$ Patients drained with 5-French open-ended catheter for 2 days

$\S$ Fischer's exact test

$\|$ tTest

II Pearson's Chi squared test

\# Pearson's Chi squared test with Yates correction
} 
showed minimal irritative symptoms (Table 2).

In addition, removal of indwelling stent constitutes an additional procedure, which not only is physical but also a financial burden to the patient especially in a developing country like India. Kim et $\mathrm{al}^{14}$ evaluated pain that occurred on cystoscopy following an intramuscular injection of diclofenac $90 \mathrm{mg}$. The mean score of VAS during the procedure was $7.8 \pm 0.7$, which indicated severe pain. In addition, only $22.5 \%$ of patients responded "yes" to a questionnaire about their willingness to submit to the same procedure again. ${ }^{14}$ Moon et $\mathrm{al}^{13}$ reported a mean VAS score of $4.96 \pm 1.29$ for stent removal using lidocaine gel. Although the mean VAS score for stent removal under local anaesthesia in our series was 3.76 , the mean for males and females was 4.97 and 2.41, respectively. This amounts to moderately severe pain in males, and in association with irritative bladder symptoms that could influence the patient's willingness to go for a repeated procedure in future if required. Besides, manipulation during the procedure to remove the stent under local anaesthesia especially in males could lead to urethral or bladder injuries, a drawback that Hollenbeck et $\mathrm{al}^{15}$ have observed.

Many have questioned the need for ureteral stenting following URS. Denstedt et $\mathrm{al}^{16}$ in a series of 58 patients who underwent URS (29 stented and 29 non-stented) reported that there was no significant difference in complications or success rates for URS between stented versus non-stented cases. However, Djaladat et $\mathrm{al}^{17}$ reported that when ureteroscopy was performed without catheterization, flank pain and renal colic could result from early ureteral oedema implying that some postoperative drainage is better than no drainage at all. This formed the premise of using the open-ended ureteral catheter in immediate postoperative period in our series and the significantly lower VAS scores suggest that their placement can be as effective as stents with minimal irritative symptoms..$^{17} \mathrm{Nabi}$ et $\mathrm{al}^{18}$ concluded that there was no significant difference in postoperative requirements for analgesia, urinary tract infection, the stone-free rate, or ureteric stricture formation in patients who underwent uncomplicated URS. There was no significant difference in analgesic requirement in the three groups in our study; 9, 11 , and 7 patients in groups 1,2 , and 3 respectively required intravenous tramadol on postoperative days 1 and 2, only one patient in group 1 needed further analgesia. No patient needed analgesics beyond the second postoperative day which is comparable to the series by Moon et $\mathrm{al}^{13}$ who reported that ratio of patients who needed intravenous analgesics because of severe postoperative flank pain was not significantly different between stented and opendrainage groups.

In our study, 20 out of 33 in group 1, 29 out of 35 in group 2, and all 31 patients in group 3 responded affirmatively when asked "Whether you would opt for the same procedure again as treatment if you develop ureteral stones in the future?" The $P$ values for willingness for repeated procedure were 0.04 and 0.0003 when comparing groups $1-2$ and 1-3 respectively, which is in line with another study (willingness $\mathrm{P}=0.02$ in favour of open-ended drainage).$^{13}$ The results show that patients in groups 2 and 3 (tamsulosin and open-catheter drainage) were significantly more likely to accept a repeated procedure if needed. Hence, it can be inferred that administration of tamsulosin following stenting or placement of open-ended catheter (removed on day 2 ) was better tolerated by patients compared with an indwelling stent-only procedure.

The relatively small sample size and being unblinded which was a likely placebo effect in the tamsulosin group were the most obvious limitations in our study. We believe that since in the stented group patients were given tablet levofloxacin $250 \mathrm{mg}$ as suppressive prophylaxis post-discharge, any relief in lower urinary tract symptoms therefore could not be attributed to tamsulosin alone as placebo effect. Assessment of VAS was done by personnel who were blinded and had no direct influence on the treatment or assessment protocol; this ruled out surgeons' bias and their involvement in influencing the patient's reporting of VAS scores. Degree of difficulty, complexity, and duration of the procedure could be construed as confounding factors in the study. However, the relatively simple inclusion and exclusion criteria which included all but the absolute indications for stenting for comparison obviate this and the results demonstrate that open-ended shortduration ureteral drainage can replace stenting in all other scenarios.

\section{Conclusion}

Accepting the limitations of a smaller sample size, open-ended catheter drainage for 2 days is better tolerated for flank pain and irritative bladder symptoms when compared with an indwelling double J stent for 2 weeks, without any significant difference in complications or efficacy. We recommend this procedure as a viable replacement to routine stenting following URS. In those patients who do undergo stenting following URS, administration of tamsulosin significantly reduces stent-related flank pain and irritative symptoms and enhances the overall quality of life. In view of the possible placebo effect on patients in group 2, the results show that there is a need for more exhaustive and larger multicentre randomised controlled trials to assess the role of tamsulosin in countering postURS stenting symptoms, given its wide acceptance for pain relief and stone passage in treating lower ureteral stones. 


\section{Declaration}

No conflicts of interest were declared by authors.

\section{References}

1. Finney RP. Experience with new double J ureteral catheter stent. J Urol 1978;120:678-81.

2. Hepperlen TW, Mardis HK, Kammandel H. Selfretained internal ureteral stents: a new approach. J Urol 1978;119:731-4.

3. Lee JH, Woo SH, Kim ET, Kim DK, Park J. Comparison of patient satisfaction with treatment outcomes between ureteroscopy and shock wave lithotripsy for proximal ureteral stones. Korean J Urol 2010;51:788-93.

4. Harmon WJ, Sershon PD, Blute ML, Patterson DE, Segura JW. Ureteroscopy: current practice and long-term complications. J Urol 1997;157:28-32.

5. Boddy SA, Nimmon CC, Jones $\mathrm{S}$, et al. Acute ureteric dilatation for ureteroscopy. An experimental study. Br J Urol 1988;61:27-31.

6. Hosking DH, McColm SE, Smith WE. Is stenting following ureteroscopy for removal of distal ureteral calculi necessary? J Urol 1999;161:48-50.

7. Wang CJ, Huang SW, Chang CH. Effects of tamsulosin on lower urinary tract symptoms due to double-J stent: a prospective study. Urol Int 2009;83:66-9.

8. Stoller ML, Wolf JS Jr, Hofmann R, Marc B. Ureteroscopy without routine balloon dilation: an outcome assessment. J Urol 1992;147:1238-42.

9. Netto Júnior NR, Claro Jde A, Esteves SC, Andrade EF. Ureteroscopic stone removal in the distal ureter. Why change? J Urol 1997;157:2081-3.

10. Pollard SG, Macfarlane R. Symptoms arising from Double-J ureteral stents. J Urol 1988;139:37-8.

11. Bregg K, Riehle RA Jr. Morbidity associated with indwelling internal stents after shock wave lithotripsy. J Urol 1989;141:510-2.

12. Han CH, Ha US, Park DJ, Kim SH, Lee YS, Kang SH. Change of symptom characteristics with time in patients with indwelling double-J ureteral stents. Korean J Urol 2005;46:1137-40.

13. Moon KT, Cho HJ, Cho JM, et al. Comparison of an indwelling period following ureteroscopic removal of stones between Double-J stents and open-ended catheters: a Prospective, pilot, randomized, multicenter study. Korean J Urol 2011;52:698-702.

14. Kim KS, Kim JS, Park SW. Study on the effects and safety of propofol anaesthesia during cytoscopy. Korean J Urol 2006; $47: 1230-5$.

15. Hollenbeck BK, Schuster TG, Faerber GJ, Wolf JS Jr. Routine placement of ureteral stents is unnecessary after ureteroscopy for urinary calculi. Urology 2001;57:639-43.

16. Denstedt JD, Wollin TA, Sofer M, Nott L, Weir M, D'A Honey RJ. A prospective randomized controlled trial comparing nonstented versus stented ureteroscopic lithotripsy. J Urol 2001;165:1419-22.

17. Djaladat H, Tajik P, Payandemehr P, Alehashemi S. Ureteral catheterization in uncomplicated ureterolithotripsy: a randomized, controlled trial. Eur Urol 2007;52:836-41.

18. Nabi G, Cook J, N'Dow J, McClinton S. Outcomes of stenting after uncomplicated ureteroscopy: systematic review and meta-analysis. BMJ 2007;334:572. 